\title{
De urbis excidio de San Agustín: razón y revelación en la comprensión de un acontecimiento histórico
}

\author{
Pamela Chávez, Aguilar \\ UNIVERSIDAD DE CHILE
}

La presente comunicación se enmarca en la relación entre fe y razón en el pensamiento de San Agustín. Dicha relación es la respuesta al hecho de que el hombre es un buscador de verdad, tiene apetito de verdad, anhelo que remite finalmente a la inseguridad de la existencia finita, que acucia el corazón y la mente humana con incertidumbres e interrogantes.

La pregunta guía es cómo se articulan fe y razón en la comprensión del hecho histórico de la devastación de Roma, en el célebre sermón agustiniano, o, dicho de otro modo, cuál es el punto de vista de San Agustín en la comprensión de tal acontecimiento.

Con este fin, creo conveniente dividir la reflexión en cinco puntos muy sencillos: la recepción de la noticia, el carácter del acontecimiento, la pregunta, el sentido y la comunicación.

\section{Recepción de la noticia}

Recibir una noticia es un acto de la ratio que implica entender (intelligere) y creer (credere), esto es, confiar en la veracidad de lo que otros nos han referido. Esta confianza es fundamento de las relaciones sociales y sin ella no habría sociedad posible; pertenece a ese género de verdades de las cuales dice Agustín que si no las creyéramos, no podríamos dar un paso en la vida (San Agustín, Conf., VI,V,7). Así expone Agustín la noticia recibida:

«Nos han anunciado cosas horrendas. Exterminios, incendios, saqueos, asesinatos, torturas de los hombres. Ciertamente que hemos oído muchos relatos escalofriantes; hemos gemido sobre todas las desgracias; con frecuencia hemos derramado lágrimas, sin apenas tener consuelo. 
Sí, no lo desmiento, no niego que hemos oído enormes males, que se han cometido atrocidades en la gran Roma» (San Agustín, De urbis excidio, II, 3).

En la recepción del acontecimiento hay un movimiento de la ratio, el anuncio del hecho catastrófico, y a la vez del creer, pues «nos han anunciado», «hemos oído» relatos de otros y les damos crédito. La noticia implica creer algo que no vemos ${ }^{1}$ : la gran Roma ha sido devastada.

Al testimonio creído que viene de otros, le sigue el movimiento de asimilación interior, donde cada uno decide que las palabras escuchadas son verdaderas o que no lo son. En este movimiento interior interviene nuevamente la ratio en cuanto juzga (iudico) y la fides en cuanto confronta lo escuchado con la voz del Maestro Interior -siguiendo el desarrollo del temprano diálogo agustiniano De magistro-, voz que le permite asentir y decir: «es así». De esta manera, el testimonio externo de Agustín - «...no niego que hemos oído enormes males...»- es precedido por el reconocimiento interior, pues: «¿de dónde sabría si decía la verdad?... la verdad sería la que me diría interiormente... "Dice verdad", y yo, certificado, diría al instante confiadamente a aquel hombre: "Dices la verdad"» (San Agustín, Conf., XI, III, 5).

\section{Carácter del acontecimiento}

Lo recibido no es un hecho cualquiera, cotidiano, sino un acontecimiento histórico, algo impensado, imprevisto, novedoso, que interrumpe el curso habitual del transcurrir vital. Pero, además, un suceso negativo y de carácter crítico, catastrófico; como el mismo Agustín lo califica, «devastador» (excidium).

¿Qué significa esto? Un evento inesperado que resulta en un real y total quiebre de la seguridad anterior en que se estaba; una crisis histórica, en el sentido de Ortega. San Agustín experimentó en carne propia el desconcierto y fue testigo del desaliento y confusión de sus contemporáneos, en particular de los cristianos, su querido rebaño para el cual el Obispo pronuncia el sermo. La destrucción de la ciudad de Roma fue un acontecimiento demoledor para los ciudadanos romanos y para los cristianos del siglo V. Se ha comparado la devastación de una ciudad -en el plano colectivo- con la muerte de un ser humano, en el plano individual. Como tal acontecer inesperado, produce desconcierto, inseguridad, sentimien-

1 San Agustín, De Fid. Rer., III, 5. 
to de desvalimiento y fragilidad. A veces se piensa que es privativo de la modernidad ese sentimiento permanente de crisis, sin considerar que nuestro tiempo no tiene el monopolio de las catástrofes históricas, cívicas o personales.

Por qué la caída de Roma tuvo ese carácter devastador, se entiende si logramos aproximarnos al significado de Roma para la antigüedad; esta era un punto de referencia para la seguridad y garantía del orden social y político $^{2}$, como ha visto Giuseppe Cannone en su comentario ya clásico a este sermón. La caída de la ciudad en manos de Alarico y su saqueo y destrucción equivalían a un inminente fin de mundo. Un pánico colectivo se apoderó de las almas y un sentimiento irracional de crisis nubló las conciencias en un mar de confusión, desesperación y desorientación. Se desvanecía el mito de la eternidad de Roma. No podemos entender totalmente esto, solo aproximarnos a esa experiencia histórica.

Para la vida del creyente, tales hechos constituyeron una herida en la fe y una amenaza de desesperación, que es el fracaso de la fe. San Agustín se propone levantar el ánimo abatido de los cristianos y darles una orientación en la comprensión del hecho que fortalezca su fe. Caídas las murallas de la ciudad, no admite Agustín también la caída de los ciudadanos, especialmente de los cristianos, de la ciudad de Dios; le preocupa el levantar las almas desde la devastación interior, pues: «Una ciudad está en sus ciudadanos, no en sus murallas» (San Agustín, De urbis excidio, VI, 6).

\section{La pregunta}

La conmoción vital y la experiencia del fracaso es un genuino origen del filosofar, decía en su tiempo Jaspers ${ }^{3}$. Ese quiebre puede dar origen a la pregunta, que es lo más propiamente filosófico. El ejercicio de la razón está sobre todo en el interrogar, buscar razones, exigir que la realidad muestre la razonabilidad que promete o que Dios manifieste su bondad y su poder. La ratio aparece en la muy humana pregunta: ¿por qué Dios permite el mal de los justos?

Un acontecimiento devastador es una conmoción de la que nace una pregunta vital. San Agustín hace suyo el dolor, conmoción y confusión de los cristianos; a ellos se dirige en el sermo. Ante un mal padecido de efectos

2 G. Cannone, «Il 'Sermo de excidio urbis Romae' di S. Agostino», Vetera Christianorum, 12 (1975) 325; 332.

3 K. Jaspers, La filosofía desde el punto de vista de la existencia (México ${ }^{21957)} 19$. 
devastadores brotan espontáneamente las interrogantes: ¿por qué?, ¿dónde está Dios?, ¿por qué castiga al inocente?

En el capítulo I del sermón, Agustín se dirige a quienes murmuran contra Dios por lo sucedido en Roma. Para responder, invita a volver la mirada a la figura bíblica del santo profeta Daniel, quien oraba a Dios y confesaba los pecados propios y de su pueblo. El reconocimiento del pecado que hace el justo Daniel es un testimonio y una respuesta: ¿quién puede ser tan arrogante -ante el ejemplo de Daniel- de considerarse a sí mismo inocente?4.

Continúa Agustín con la pregunta: ¿por qué Dios no ha perdonado a Roma por los justos?, ¿no había en Roma ni siquiera cincuenta, cuarenta, treinta ni diez justos?, haciendo referencia a la conversación bíblica entre Abraham y Dios, en que el primero intercede por la ciudad de Sodoma ${ }^{5}$. San Agustín previene con una sentencia contra la errada interpretación del texto bíblico: «La Escritura no engaña cuando el hombre no se engaña a sí mismo» (San Agustín, De urb. exc., II, 2). Para Agustín no es nada claro que Dios no haya perdonado a la ciudad o manifestado su misericordia; comparada con Sodoma, que fue destruida totalmente, Roma solo fue castigada y no todos sus hombres exterminados: «icuántos salieron y volverán, cuántos se quedaron y se han librado; cuántos ni siquiera pudieron ser tocados en los lugares santos!» (San Agustín, De urb. exc., II, 2).

Agustín responde: ciertamente había muchos hombres humanamente justos en Roma y por ellos Dios tuvo misericordia, algunos huyeron y los que murieron fueron perdonados. Padecieron, pero han sido glorificados y, como el mendigo a la puerta del rico, han sido «llevados por los ángeles al seno de Abraham» (San Agustín, De urb. exc., V, 5).

Pero la interrogante prosigue: pero muchos han padecido crueles tormentos. Ante esto, Agustín pone otra figura bíblica, Job, el justo sufriente, comparando la devastación de Roma con los males de Job, quien padeció y resistió la destrucción de su hacienda, la muerte de sus seres queridos, la herida abierta de su carne, la desolación interior y la tentación. Job resistió el mal y no blasfemó, mostrando que en medio de sus intensos males conservó la inocencia del corazón.

La probada justicia de Job permite a San Agustín mostrar el abismo infinito que existe entre el mal padecido y el mal que se hace: «iQue nadie se fije en lo que sufre, sino en lo que hace! Hombre, lo que tú padeces no

\footnotetext{
4 San Agustín, De urb. exc., I, 1.

5 Gen. 18, 23-32.
} 
está en tu poder; en cambio, tu voluntad es culpable o inocente en lo que tú haces» (San Agustín, De urb. exc., III, 3). La pregunta insondable ante el mal padecido es respondida por Job y por San Agustín con otra pregunta: «Si aceptamos de Dios los bienes, ¿no vamos a aceptar los males? Dios es un Padre: ¿va a ser amado cuando acaricia, y despreciado cuando corrige?» (San Agustín, De urb. exc., III, 3).

Otra comparación realiza Agustín: los sufrimientos temporales, aun los más grandes que puedan ser pensados, se muestran insignificantes al lado de las penas del infierno, en que se trata de un sufrir eterno.

Mediante la referencia a Constantinopla -que ante una amenaza se convirtió e hizo penitencia como los ninivitas en el relato bíblico- San Agustín expresa una razón más ante la pregunta por el mal padecido: Dios busca la conversión de los pecadores, que es un gran bien.

La misma tribulación sufrieron en Roma los justos y los pecadores; estos, como condena; los primeros, como prueba y aprendizaje de «cuán inestables y caducas son todas las vanidades del siglo» (San Agustín, De urb. exc., VIII, 9).

Finalmente, el sufrimiento de los justos no puede dejar de enlazarse con el sufrimiento del Señor, el «Justo de los justos y el Santo de los santos» (San Agustín, De urbis excidio, VIII, 9). El mal padecido ha de ponerse en una balanza con el mal padecido por Cristo, ante lo cual ha de callar toda pregunta: «Pon en balanza a Roma con Cristo, sopesa la tierra entera y a Cristo, equilibra cielo y tierra con Cristo; nada creado puede valorarse con el Creador, ni obra alguna se compara con el Autor» (San Agustín, De urbis excidio, VIII, 9). El mal padecido por el Señor de señores es una respuesta testimonial a la interrogante que acucia el espíritu humano, al misterio del sufrimiento del inocente: «Fijaos quién es ese uno. El Rey de reyes y Señor de señores, apresado, atado, flagelado, zarandeado con toda clase de afrentas, colgado y clavado en una cruz, muerto...» (San Agustín, De urbis excidio, VIII, 9).

\section{El sentido}

El Obispo de Hipona se encuentra ante un rebaño atemorizado y desalentado, sus almas turbadas, su razón confundida. Su objetivo será entonces intentar elevar la mirada de los cristianos desde los hechos terrenos desnudos -«exterminios, incendios, saqueos, asesinatos, torturas, atrocidades»... 
(San Agustín, De urbis excidio, II, 3), la caída de la «inmortal Roma»- hacia su sentido sobrenatural, es decir, mirarlo desde la fe. Por eso el sermón transita hacia una interpretación moral del acontecimiento, evitando quedarse anclado en la contemplación de la caída material y moral de Roma y fijando la mirada en su causa -el mal del pueblo o el propio mal, como el profeta Daniel hace ante la ruina del pueblo hebreo- y en la comprensión de su sentido último.

Desde el hecho particular, San Agustín eleva la mirada hacia el sentido del mal en la historia, la cual para el cristianismo responde a un plan salvífico de Dios. Agustín busca mostrar el sentido salvífico del acontecimiento y encuentra para ello su apoyo en la Sagrada Escritura y en figura de tres justos enfrentados a la tribulación: Noé, Daniel y Job. Es la revelación la que pone la roca firme tras el anuncio de lo horrendo inesperado: Dios no se ha retirado de la historia, los justos no han sido abandonados, el amor y la bondad de Dios no son contradictorios con la tribulación.

Para San Agustín, solo la fe puede dar el sentido auténtico (verus) del acontecimiento, que es un sentido sobrenatural. La fe es el punto de vista para entender la historia humana y el plan divino para el hombre, desde la creación, pasando por la caída y redención, hasta el fin último, hasta «aquella felicidad, donde no habrá mal alguno, donde no faltará ningún bien, donde toda ocupación será alabar a Dios, que será el todo para todos» (San Agustín, Civ. Dei, XXII, XXX, 1).

Así, no puede haber comprensión cabal del acontecimiento histórico sin esta mirada escatológica; la mirada humana es inevitablemente estrecha e incompleta, pues el ser humano es conocedor de partes. Requiere la mirada de quien ve todo, hasta el fin de la historia, esto es, la mirada de Dios, por lo que la búsqueda de una comprensión total debe dar paso a la categoría del misterio.

\section{La comunicación}

El texto que nos ocupa tiene la forma de un sermo, atribuido con gran probabilidad a Agustín y escrito muy poco tiempo después de acaecida la invasión y destrucción de Roma, el 24 de agosto de 410. El tema del sermón responde a la profunda implicación y responsabilidad de Agustín con los problemas de su época, la que a su vez manifiesta el valor que para él tenía la realidad misma ${ }^{6}$. Este sermón anticipa la exposición más

6 G. Cannone, «Il 'Sermo de excidio urbis Romae' di S. Agostino», 346. 
sistemática que realizará en De civitate Dei, donde reúne las reflexiones en torno al problema del mal que habían sido expresadas en el sermón de un modo más coloquial.

La forma del sermón ya es indicativa de su doble mirada: la intencionalidad comunicativa del discurso y las argumentaciones dadas trasuntan su componente racional; la intencionalidad pastoral e incluso apologética del texto lo sitúan en el plano de la fides. Sermo es una forma del enseñar en público (prodoceo), del pensar con intencionalidad de comunicar a otros. Supone la fe en lo que decimos u otro dice, confianza y experiencia intersubjetiva. Como tal, el sermo es un acto racional que implica varios actos, vía ratio. En efecto, podemos decir que sermo es un tipo de acto de habla, un acción comunicativa y un acto ilocucionario -en el sentido de Searle y Austin ${ }^{7}$ - pues en él se enuncian proposiciones de un hablante a un oyente o auditorio, que toman la forma al menos del informar, explicar, mostrar, argumentar, aconsejar. Por ello hay un contenido proposicional (informar los hechos terribles ocurridos en Roma; afirmar y argumentar o dar razones respecto a que este mal no es incompatible con la bondad y omnipotencia de Dios y el orden o plan salvífico de Dios). Ello supone varias reglas, como la de la sinceridad, la de creer que algo es verdadero, de que algo beneficiará al otro (aconsejar), de que hay razones para creerlo así. Pero implica también creencias previas: que Dios es la verdad y la fe en la revelación.

En el sermón de Agustín, las razones dadas ante la pregunta por el mal de los justos, buscan afirmar la fe, que esta no sea devastada también por la confusión del pensamiento. La razón quiere despejar las dudas para que la fe continúe su crecimiento en paz, más sólidamente fundamentada. La razón no es reductible a la fe ni al revés, pero la razón puede ser uno de los pilares contra los ataques a la fe que vienen de la razón, contra el desconcierto o la insecuritas vital, especialmente dramática en momentos de catástrofe.

\section{Epílogo}

Habíamos emprendido la tarea de identificar en el sermón De urbis excidio el modo agustiniano de comprender e interpretar desde la ratio y la fides un acontecimiento histórico.

J. Searle, Actos de habla. Ensayo de filosofía del lenguaje., trad. de L.Valdés Villanueva. (Madrid ${ }^{3}$ 1990) 32. 
En el sermón, Agustín se devela simultáneamente como el hombre preocupado por las realidades de su tiempo, como el pastor responsable de su desconcertado rebaño, como el filósofo acuciado por la pregunta del sentido del mal padecido en la historia humana. Para comprender el acontecimiento y enseñar a los cristianos, San Agustín tiene una sola respuesta: Cristo. La seguridad y la paz frente a la devastación de Roma solo puede provenir de la fe en Él. Escuchando el sermón en nuestro presente, pareciera sentirse la fuerza de Agustín diciendo: «Soportemos entonces lo que Dios tenga permitido que soportemos» (San Agustín, De urbis excidio, VIII, 9), porque, como expresa citando a San Pablo: «Fiel es Dios, que no permitirá que seáis tentados sobre vuestras fuerzas, sino que, para poder vencer, os dará con la tentación también el éxito» (San Agustín, De urbis excidio, VIII, 9; 1 Cor 10,13).

La devastación de Roma no es el fin del mundo y de la historia. Es un gran mal que Dios puede transformar en bien, como el perfeccionamiento de los justos y, por tanto, de la Ciudad definitiva. Finalmente, siguiendo a Cannone, podemos decir que Agustín contempla la devastación de Roma a través de Cristo, pues su pensamiento parte de Cristo y llega a Cristo.

Resumen: Este artículo se propone investigar la relación entre fe y razón en el pensamiento de san Agustín. En este sentido, la pregunta clave que guía el estudio es cómo articular esta relación a partir del hecho histórico de la devastación de Roma recogida en el sermón de urbis excidio. De esta manera, la relación fe-razón es la respuesta que remite, finalmente, a la inseguridad de la existencia finita, que acucia el corazón y la mente humana con incertidumbres e interrogantes. Esta investigación se articula en cinco partes: la recepción de la noticia, el carácter del acontecimiento, la pregunta, el sentido y la comunicación.

Palabras clave: Agustín, fe y razón de urbis excidio.

Abstract: This article aims to investigate the relationship between faith and reason in the thought of Saint Augustine. The key question guiding the study is how to articulate this relationship, starting from the historical fact of Rome's devastation contained in the sermon de urbis excidio. Thus, the faith-reason relationship is the answer which, in the end, refers to the insecurity of finite existence, which besets the human mind with uncertainties and questions. This investigation is divided into five parts: receiving the news, the character of the event, the question, meaning and communication.

Key words: Augustine, faith and reason de urbis excidio. 